\section{Reply from the authors}

Dear Sir,

Dr. Grundbacher's comments on the analysis of the genetics of Type 1 (insulin-dependent) diabetes mellitus are that: (1) a polygenic approach is required to unravel the genetics of Type 1 diabetes mellitus using methods such as inheritance of liabilities and (2) the HLA antigens should be taken into account in any such analysis.

We must agree with both points, and, to this end, have recently investigated the relative importance of markers on chromosome 6 (HLA-DR antigens) and chromosome 11 (the 5' flanking hypervariable region of the insulin gene) in fourteen Type 1 diabetic pedigrees [1]. In order to identify and follow the inheritance of insulin gene related alleles unambiguously, we adopted a haplotyping strategy [2], using the hypervariable region 3' to the c-Harvey-ras-1 proto-oncogene (cHa-ras) [3] as an additional chromosome 11 short-arm marker.

A pedigree analysis (Table 1) revealed that, within a particular family, individuals who were haplo-identical to the diabetic proband on both homologous chromosomes 11 had a 4/13 (31\%) chance of being diabetic; if they were haplo-identical on one or neither chromosome, their chance of being diabetic was $9 / 38(33 \%)$. Similarly, individuals who were haplo-identical to the proband on one or both chromosomes had $12 / 48(25 \%)$ chance of diabetes, whereas $1 / 3$ $(33 \%)$ of subjects who shared no common chromosome 11 haplotype with the proband had diabetes. In contrast, a similar analysis for the HLA-DR locus showed that a significantly greater proportion of first degree relatives, who were HLA identical to the proband, were also diabetic $(6 / 8)$ compared with those who were HLA non-identical $(7 / 48)(p<0.001$, compared in a $2 \times 2$ contingency table and applying a chi-square test)

Table 1. The number of affected and unaffected relatives who possess shared haplotypes compared with probands of 14 type 1 diabetic pedigrees

\begin{tabular}{|c|c|c|c|c|}
\hline \multirow{2}{*}{$\begin{array}{l}\text { Number of homolo- } \\
\text { gous chromosomes at } \\
\text { which haplo-identical } \\
\text { to proband }\end{array}$} & \multicolumn{2}{|c|}{$\begin{array}{l}\text { Ins/c-Ha-ras locus } \\
\text { (chromosome 11) }\end{array}$} & \multicolumn{2}{|c|}{$\begin{array}{l}\text { HLA (DR) locus } \\
\text { (chromosome 6) }\end{array}$} \\
\hline & $\begin{array}{l}\text { Diabetic } \\
n\end{array}$ & $\begin{array}{l}\text { Non- } \\
\text { diabetic } \\
n\end{array}$ & $\begin{array}{l}\text { Diabetic } \\
n\end{array}$ & $\begin{array}{l}\text { Non- } \\
\text { diabetic } \\
n\end{array}$ \\
\hline Neither & 1 & 2 & 0 & 7 \\
\hline One chromosome & 8 & 27 & 7 & 34 \\
\hline Both chromosomes & 4 & 9 & 6 & 2 \\
\hline
\end{tabular}

These data, though preliminary, suggest that the genetic contribution of the HLA locus is of greater importance than loci on the short arm of chromosome 11 for the inheritance of diabetes mellitus. Sufficient numbers are not, available for a formal heritability analysis to confirm these observations, but may become so if a multi-centre approach is adopted.

Yours faithfully,

G. A.A. Ferns, R.C.Trembath, G. A. Hitman and D.J.Galton

\section{References}

1. Ferns GAA, Hitman GA, Trembath RC, Williams L, Tarn A, Gale E, Galton DJ (1986) A comparison of markers on chromosome 11 and 6 in the inheritance of type 1 diabetes. Clin Sci 70:32

2. Ferns GAA, Hitman GA, Trembath RC, Williams L, Tarn A, Gale E, Galton DJ (1986) DNA polymorphic haplotypes on the short arm of chromosome 11 and the inheritance of type 1 diabetes mellitus. Journal of Medical Genetics (in press)
3. Capon DJ, Chen EY, Levison AD, Seeberg PH, Goeddel DV (1983) Complete nucleotide sequence of the T24 bladder carcinoma oncogene and its normal homologue. Nature 302, 33-37

\section{Dr. G.A.A. Ferns}

Department of Medicine

St. Bartholomew's Hospital

London ECI, UK

\section{Aprotinin on insulin absorption and subcutaneous blood flow}

Dear Sir,

We were interested to read that Linde and Gunnarsson [1], using the $133-\mathrm{Xe}$ washout technique to measure subcutaneous blood flow, have confirmed our observation that subcutaneously-injected aprotinin causes local hyperaemia [2].

Linde and Gunnarsson suggest that the increase in blood flow after aprotinin injection, which we recorded using the optical technique of photoelectric plethysmography [3], might have been due simply to injection trauma in the superficial tissues. However, in our study we allowed for the non-specific effects of injection, such as trauma and tissue distension, by comparing the hyperaemic effect of aprotinin (Trasylol, Bayer) with that of Trasylol diluent. Figure 1 shows that injection of diluent caused only a brief hyperaemic flare (which seems to be a non-specific response to injection [3]) in five stable Type 1 (insulin-dependent) diabetic patients. By contrast, injection of an equal volume of aprotinin caused prolonged hyperaemia lasting ove्r $60 \mathrm{~min}$.

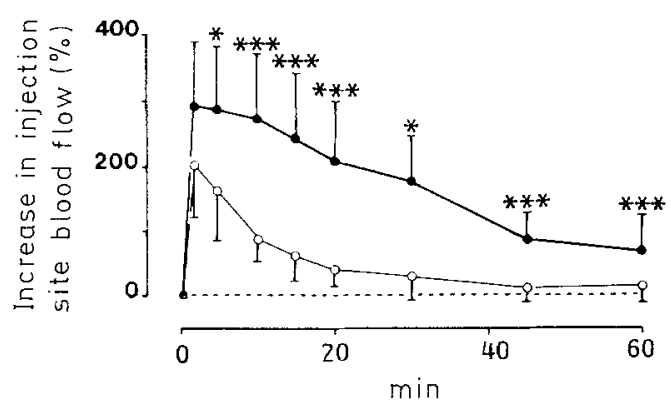

Fig. 1. Changes in blood flow (mean \pm SEM) in 5 stable Type 1 (insulin-dependent) diabetic patients, at injection sites of aprotinin $(-)$ and of aprotinin diluent $\left(\mathrm{O}^{-} \mathrm{O}\right)$, measured by photoelectric plethysmography [from 2]

Acceleration of insulin absorption by stimulating subcutaneous blood flow is potentially benefical. We have demonstrated that addition of the vasodilator and hyperaemic agent, prostaglandin $\mathrm{El}$, to subcutaneously-injected insulin also accelerates the early phase of insulin absorption and enhances insulin's hypoglycaemic effect [4]. Mixture of insulin with agents selected for their local hyperaemic action rather than their anti-protease activity may therefore be of practical use in diabetic management [5], although further work is needed to establish the mechanism through which these agents operate. Yours faithfully,

\section{G. Williams and J. Pickup}

\section{References}

1. Linde B, Gunnarsson R (1985) Influence of aprotinin on insulin absorption and subcutaneous blood flow in Type 1 (insulin-dependent) diabetes. Diabetologia 28: 645-648 
2. Williams G, Pickup JC, Bowcock S, Cook E, Keen H (1983) Subcutaneous aprotinin causes local hyperaemia: A possible mechanism by which aprotinin improves control in some diabetic patients. Diabetologia 24:91-94

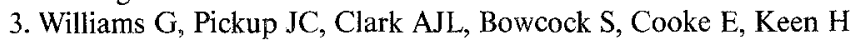
(1983) Changes in blood flow close to subcutaneous insulin injection sites in stable and brittle diabetics. Diabetes 32: 466-473

4. Williams G, Pickup JC, Collins AGC, Keen H (1984) Prostaglandin $\mathrm{El}$ accelerates subcutaneous insulin absorption in insulin-dependent diabetic patients. Diabetic Medicine 1:109-112

5. Williams G (1985) Blood flow at insulin injection sites. In: Pickup JC (ed) Brittle diabetes. Blackwell, Oxford, pp 132-153

Dr. G. Williams

Endocrine Unit

Hammersmith Hospital

London W12 OHS

UK

\section{Dr. J.Pickup}

Department of Chemical Pathology

Guy's Hospital Medical School

London SE1 9RT

UK

\section{Diet and Type 1 (insulin-dependent) diabetes}

Dear Professor Berger,

I read with interest the article by McCulloch et al. [1] examining "Imaginative and Practical Teaching Methods" as influences on dietary compliance and metabolic control in Type 1 (insulin-dependent) adults. It is widely accepted that the gulf between the theory and practice of dietary treatment in diabetes is large, and measures to reduce this gulf are to the welcomed.

It is important, however, not to take the results of a single study of groups of 12 patients chosen for their poor control to suggest that modern diabetic diets reducing total fat and increasing fibre (especially gel fibre) are not of value. The fairly broad consensus for the treatment of diabetic patients [2] is based on a very wide range of published papers and studies, and is not aimed solely at the improvement in blood glucose levels. The authors talk of improving metabolic control in their study patients, but report only glycosylated haemoglobin levels and not cholesterol or other metabolic parameters.

Specific comments need to be made about the study itself:

1. The compliance of patients taking part in studies of between 15 and 19 months duration may vary, and this may be evident from the gly- cosylated haemoglobin results for the control group A in the second part of their 15-month study.

2. To study the experimental group for 4 months longer than the two control groups is likely to bias results.

3. The drop-out of two patients from the conventional diet group B may distort results by the inclusion of more compliant patients. This might be a reason why the group B patients, reduced to 10 , had glycosylated haemoglobins $1 \%$ lower than the other two groups. While not statistically different, this may be sufficient to affect later results.

4. In respect of glycosylated haemoglobin values, those given in Figure 3 seem to have standard error bars inappropriately small for the values given in Table 1 and given in the text.

The authors may have achieved some improvement in diabetic control in their patients by their teaching programme, and I would agree that consistency and timing of carbohydrate intake is very important. Their study does not show that a low fat, high fibre, high complex carbohydrate diet does not improve diabetic control.

Few of their high fibre patients were shown to increase gel fibre sources (Table 3 ). Only moderate increases in total fibre intake were seen, to a level actually matched by the Group B patients, who were not given the dietary advice in the second intervention period. One may therefore conclude that the teaching in the second intervention period was unsuccessful, rather than conclude that the dietary recommendations of the British Diabetic Association and of others are not valid.

Yours sincerely,

J. Reckless

Chairman, Nutrition Sub-Committee, British Diabetic Association

\section{References}

1. McCulloch DK, Mitchell RD, Ambler J, Tattersall RB (1985) A prospective comparison of "conventional" and high carbohydrate/ high fibre/low fat diets in adults with established Type I (insulindependent) diabetes. Diabetologia 28:208-212

2. Statement by the British Diabetic Association (1982) Dietary recommendations for diabetes for the 1980s. Hum Nutr Appl Nutr 36a: $378-394$

\section{Dr. John Reckless}

Royal United Hospital

Combe Park

Bath BA1 3NG

UK

\section{Erratum}

Diabetologia, Volume 29, Number 1, January 1986, p. 22

Article by W. Burger et al.: Prevalence and development of retinopathy in children and adolescents with Type 1 (insulin-dependent) diabetes mellitus. A longitudinal study

Please note that in the fourth sentence in the last paragraph of the above-mentioned paper, the word proliferative should be replaced by pre-proliferative. This sentence should read:

'Only 5 years later, retinal changes reach the pre-proliferative state of no return.'

The publisher regrets that this correction was not carried out before going to press. 